\title{
Amidomethylation of Vinyl Aromatic Polymers with $N$-Methylol-2-chloroacetamide
}

\author{
Kazuo TERAMOTO**** and Yoshiaki NAKAMOTO* \\ * Graduate School of Natural Science and Technology, Kanazawa University, \\ 2-40-20 Kodatsuno, Kanazawa 920-8667, Japan \\ ${ }^{* *}$ Pioneering Research Laboratories, Toray Industries, Inc., \\ Sonoyama, Otsu 520-0842, Japan
}

(Received December 3, 2001; Accepted March 22, 2002)

\begin{abstract}
New vinyl aromatic compound polymers containing 2-chloroacetamidomethyl groups have been prepared from the corresponding polymers by amidomethylation with $\mathrm{N}$-methylol-2-chloroacetamide (NMCA). The reaction proceeds in nitrobenzene or nitropropane in the presence of sulfuric acid as catalyst at temperature of 10 to $25^{\circ} \mathrm{C}$. When 1.1 molar or less than 0.3 molar of NMCA to a molar of polystyrene is used, a soluble polymer is obtained. From poly(4-methylstyrene) or poly(4-tert-butylstyrene), soluble polymers containing 2-chloro-acetamidomethyl group are also obtained by the same reaction. ${ }^{1} \mathrm{H}$ NMR, ${ }^{13} \mathrm{C}$ NMR, FT-IR spectroscopy, and elemental analysis identifies the structures. These polymers are soluble in DMF or chloroform. In the case of poly(4-methylstyrene), NMR analysis shows that meta substituted product is exclusively obtained, although there are two possibilities of ortho- and meta-substituted products.

KEY WORDS N-Methylol-2-chloroacetamide / Amidomethylation Reaction / Polystyrene /

Poly(4-methylstyrene) / Poly(4-tert-butylstyrene) / 2-Chloro-acetamidomethyl Group /
\end{abstract}

Since polystyrene is one of the most popular plastics, many chemical modifications of polystyrene, e.g., sulfonation, ${ }^{1}$ acylation, ${ }^{2}$ nitration, ${ }^{3}$ and chloromethylation, ${ }^{4}$ have been reported. Amidomethylation of styrene-divinylbenzene beads with $N$-methylol phthalimide was studied by Merrifield to obtain the aminomethylated beads. ${ }^{5}$ On the other hand we developed the amidomethylation of polystyrene fibers ${ }^{6}$ and dishes ${ }^{7}$ using NMCA as amidomethylating reagent, by which the benzene ring of the polystyrene was quantitatively substituted by a chloroacetamidomethyl group that was easily converted into various functional groups. ${ }^{8}$ The amidomethylation reaction could be performed at the temperature below $25^{\circ} \mathrm{C}$ in a short time. Moreover, the preparation and the handling of NMCA were easy, because NMCA was liable to crystallize, and the crystal was nonhygroscopic. The replacement of the chlorine with amino compounds proceeded readily under mild condition. Thus, polymyxin B was immobilized on the chloroacetamidomethylated fiber, and the resulting fiber had an endotoxin adsorbing capacity. The fibers were packed in column for hemoperfusion, and used for the treatment against sepsis shock. ${ }^{9}$

The purpose of the amidomethylation of the polystyrene fiber was to prepare a carrier for immobilization of various compounds. As noted above, the degree of substitution (DS) of the benzene ring of the polystyrene was almost $100 \%$. This DS is too high for the immobilization of large molecules such as polymyxin B, cyclic decapeptide; because most of the amidomethyl group will remain unused judging from that the molecular weight of polymyxin B is about five times that of styrene unites. However, it was difficult to lower DS in such solid-liquid reaction. If the reaction is performed in a homogeneous solution, the density of the amidomethyl group is easy to be controlled. In this report, the synthesis of soluble amidomethylated polymer in homogeneous solution is reported.

\section{EXPERIMENTAL}

\section{Materials}

Polystyrene $(n=1600-1800)$ was obtained from Wako Pure Chemical Co., Osaka, Japan. Poly(methylstyrene) $(60 \%$ meta, 40\% para; $\mathrm{FW}=80000)$, poly(4-methylstyrene) $(\mathrm{FW}=11500)$, and poly(4-tertbutylstyrene) were purchased from General Science Corp., Tokyo, Japan. Other reagents were commercially available as guaranteed grade, and used without further purification. NMCA was prepared following the previous paper. ${ }^{7}$ Namely, a mixture of 2-chloroacetamide $(1 \mathrm{~kg})$, paraformaldehyde $(345 \mathrm{~g})$, potassium carbonate $(50 \mathrm{~g})$, and water $(1 \mathrm{~L})$ was heated at $50^{\circ} \mathrm{C}$ to form a homogeneous solution, and then cooled to $5^{\circ} \mathrm{C}$ to let NMCA crystallize out of it. The crystalline solid was filtered, and washed with cold water $(300 \mathrm{~mL})$, followed by vacuum drying at $25^{\circ} \mathrm{C}$. Yield $789 \mathrm{~g}, \mathrm{mp} 101.5-103.0^{\circ} \mathrm{C}$. 


\section{Measurements}

Infrared spectra were recorded on a Shimadzu Fourier Transform Spectrometer 4300 using KBr discs or thin films, which were prepared by casting their chloroform solutions on a glass plate. Elemental analysis (\% CHN, S, Cl) , $400 \mathrm{MHz}{ }^{1} \mathrm{H}$ NMR, ${ }^{13} \mathrm{C} \mathrm{NMR}$, and $400 \mathrm{MHz} \mathrm{HMBC}$ analysis were performed by Toray Research Center, Kamakura, Kanagawa, Japan.

The ${ }^{13} \mathrm{C}$ and ${ }^{1} \mathrm{H}$ NMR spectra of samples were recorded with a JEOL JNM-GSX-400 and EX-270 spectrometer. Deuterated dimethyl sulfoxide (DMSO$\left.d_{6}\right)$ and deuterated chloroform $\left(\mathrm{CDCl}_{3}\right)$ were used as solvent, and TMS was used as an internal reference. The spectra of the polymers were run at $30^{\circ} \mathrm{C}$ in a $7 \%$ $(\mathrm{w} / \mathrm{v}) \mathrm{DMSO}-d_{6}$ or $\mathrm{CDCl}_{3}$ solution.

\section{Amidomethylation Reaction}

(1) Preparation of Amidomethylating Solution.

NMCA (7.0 g) was dissolved in a mixture of sulfuric acid $(50 \mathrm{~mL})$ and nitrobenzene $(25 \mathrm{~mL})$, or 1 nitropropane $(25 \mathrm{~mL})$ at a temperature of -5 to $3^{\circ} \mathrm{C}$ with stirring. The resulting solution was immediately used in the next reaction. The density of the solution was $1.60 \mathrm{~g} \mathrm{~mL}^{-1}$ for nitrobenzene and $1.50 \mathrm{~g} \mathrm{~mL}^{-1}$ for 1-nitropropane.

(2) General Procedure of Amidomethylation. The amidomethylating solution was added to the nitrobenzene or 1-nitropropane solution containing polystyrenes at $10^{\circ} \mathrm{C}$ with stirring, and stirred for $2 \mathrm{~h}$ at $10-15^{\circ} \mathrm{C}$. The reaction mixture was put into cold methanol $\left(-20^{\circ} \mathrm{C}\right)$. The precipitate was filtered off, washed with methanol to remove sulfuric acid, and extracted with methanol in a soxhlet extractor to remove nitrobenzene or 1-nitropropane. After being dried in vacuo at $25^{\circ} \mathrm{C}$, it was dissolved in $N, N$ dimethylformamide (DMF) or chloroform, and reprecipitated with methanol for purification.

(3) Amidomethylation of Polystyrene. a. Poly(4chloroacetamidomethyl-styrene). The amidomethylating solution (127 g; $56 \mathrm{mmol}$ of NMCA) was mixed with $100 \mathrm{~mL}$ of nitrobenzene containing polystyrene (5.3 $\mathrm{g} ; 51 \mathrm{mmol})$, and stirring was continued for $2 \mathrm{~h}$ at $10-15^{\circ} \mathrm{C}$, although a slight precipitate (dark red) was produced. The product is brittle polymer, and soluble in DMF, but insoluble either in dimethyl sulfoxide or in chloroform. Yield : $8.6 \mathrm{~g}$. IR $\left(\mathrm{KBr}, \mathrm{cm}^{-1}\right)$ : $3308(\mathrm{NH})$, $2920\left(\mathrm{CH}_{2}\right), 1657$ and $1529(\mathrm{C}=\mathrm{O}$, amide 1 and 2$)$, and 1512 (bz. ring). Anal. Found: C, 61.9\%, H, 5.6\%, N, $6.6 \%, \mathrm{Cl} 15.5 \%$. Calcd. for $\mathrm{C}_{11} \mathrm{H}_{12} \mathrm{NOCl}$ (100\% substituted): C, 63.01\%; H, 5.73\%; N, 6.68\%; Cl, 16.91.

b. Partially Substituted Derivatives. For $10 \%$ substituted derivatives, the amidomethylating solution (58 g; $25.5 \mathrm{mmol}$ of NMCA) was mixed with $450 \mathrm{~mL}$ of ni- trobenzene containing polystyrene (26.5 g; $255 \mathrm{mmol})$. The product is brittle polymer, and soluble in DMF, in DMSO, or in chloroform. Yield: $28.1 \mathrm{~g}$. IR (film from the chloroform solution, $\left.\mathrm{cm}^{-1}\right): 3400,3300(\mathrm{NH}), 1676$ and $1528(\mathrm{C}=\mathrm{O}$ amide 1 and 2$)$, and 1601, $1493(\mathrm{bz}$. ring). Anal. Found: C, 86.2\%, H, 7.5\%, N, 1.7\%, $\mathrm{Cl} 2.7 \%$. Calcd. for $\mathrm{CHNOCl}$ (10\% substituted): C, $87.4 \%$; H, 7.4\%; N, 1.1\%; C1 2.8\%.

(4) Chloroacetamidomethylated Poly(3(4)-methylstyrene). The amidomethylating solution (120 g; $53 \mathrm{mmol}$ of NMCA) was added to $100 \mathrm{~mL}$ of nitrobenzene containing poly(3(4)-methyl-styrene) (6.0 $\mathrm{g} ; 51 \mathrm{mmol})$. The product is brittle polymer, and soluble in DMF or DMSO, but insoluble in chloroform. Yield: $10.8 \mathrm{~g}$. IR $\left(\mathrm{KBr}, \mathrm{cm}^{-1}\right)$ : $3290(\mathrm{NH}), 1659$ and 1528 ( $\mathrm{C}=\mathrm{O}$ amide 1 and 2 ), and 1612 (benzene ring). Anal. Found: C, 63.9\%, H, 6.3\%, N, 6.2\%, Cl 15.2\%. Calcd. for $\mathrm{C}_{12} \mathrm{H}_{14} \mathrm{NOCl}$ (100\% substituted): C, $64.4 \%$; $\mathrm{H}, 6.3 \%$; N, 6.3\%; Cl, 15.9 .

The above amidomethylated polymer (6.0 g) was heated in hydrochloric acid for $8 \mathrm{~h}$ for hydrolysis of the amide bond, and mixed with aqueous ammonia to precipitate aminomethylated polymer. Yield: $4.7 \mathrm{~g}$. IR $\left(\mathrm{KBr}, \mathrm{cm}^{-1}\right)$ : 2000-3500 $\left(\mathrm{NH}^{+}\right)$, (The peak of $\mathrm{C}=\mathrm{O}$ amide 1 and 2 disappeared), and $1593 \mathrm{~cm}^{-1}$ (benzene ring).

(5) Poly(3-chloroacetamidomethyl-4-methylstyrene). The amidomethylating solution $(131 \mathrm{~g} ; 58 \mathrm{mmol}$ of NMCA) was added to $100 \mathrm{~mL}$ of nitrobenzene containing poly(4-methyl styrene) $(6.0 \mathrm{~g} ; 51 \mathrm{mmol})$. The product is soluble in DMF or DMSO, but insoluble in chloroform. Yield: $8.6 \mathrm{~g}$. IR $\left(\mathrm{KBr}, \mathrm{cm}^{-1}\right)$ : 3300(NH), 1660 and $1528(\mathrm{C}=\mathrm{O}$ amide 1 and 2$)$, and $1593 \mathrm{~cm}^{-1}$ (benzene ring). Anal. Found: C, 63.3\%, H, 6.4\%, N, 6.1\%, Cl 15.1\%. Calcd. for $\mathrm{C}_{12} \mathrm{H}_{14} \mathrm{NOCl}$ (100\% substituted): C, 64.4\%; H, 6.3\%; N, 6.3\%; Cl, 15.9 .

To hydrolyze the amide group, the above amidomethylated polymer $(6.0 \mathrm{~g})$ was heated in hydrochloric acid for $8 \mathrm{~h}$, and neutralized with $1 \mathrm{M}-$ $\mathrm{NaOH}$. Yield: $4.0 \mathrm{~g}$. IR $\left(\mathrm{KBr}, \mathrm{cm}^{-1}\right): 3361,3283$ $(\mathrm{NH})$, and 1593, 1448 (bz. ring). The peak of $\mathrm{C}=\mathrm{O}$ amide 1 and 2 disappeared.

(6) Amidomethylation of Poly(4-t-butylstyrene). The amidomethylating solution (1-nitropropane $23 \mathrm{~mL}$, sulfuric acid $46 \mathrm{~mL}$, NMCA $9.2 \mathrm{~g} ; 74 \mathrm{mmol}$ ) was added to $100 \mathrm{~mL}$ of nitropropane containing poly(4- $t$ butylstyrene) (5.0 g; $31 \mathrm{mmol})$. The product is brownish brittle polymer, and soluble in chloroform, but insoluble in DMF and dimethyl sulfoxide. Yield: $5.8 \mathrm{~g}$. IR $\left(\mathrm{KBr}, \mathrm{cm}^{-1}\right)$ : 3429, $3332(\mathrm{NH}), 1688$ and 1682 ( $\mathrm{C}=\mathrm{O}$ amide 1 and 2 ), and 1512 (benzene. ring). Anal. Found: C, $80.1 \%, \mathrm{H}, 9.2 \%, \mathrm{~N}, 2.3 \%, \mathrm{Cl}, 4.8 \%$. 
Table I. Amidomethylation reaction of polystyrene

Polystyrene solution ( $5.3 \mathrm{~g}$ in $100 \mathrm{~mL}$ of NP or NB) was mixed with amidonethylating solution and stirred for $2 \mathrm{~h}$ at room temperature. Amidomethylating solution; NMCA 5.6\%, sulfuric acid 73.8\%, NP $20.6 \%$ or NMCA 5.8\%, sulfuric acid 71.0\%, NB 23.2\%

\begin{tabular}{|c|c|c|c|c|c|c|c|c|c|}
\hline \multicolumn{2}{|c|}{ Reaction conditions } & \multicolumn{6}{|c|}{ Reaction products } & \multirow{3}{*}{$\begin{array}{l}\text { DS from } \\
\mathrm{N} \text { content }\end{array}$} & \multirow{3}{*}{$\begin{array}{l}\text { DS } \\
\text { from NMR } \\
(\%)\end{array}$} \\
\hline \multirow{2}{*}{$\begin{array}{l}\mathrm{NMCA} / \mathrm{RU} \\
(\mathrm{mol} / \mathrm{mol})\end{array}$} & \multirow[t]{2}{*}{ Solvent } & \multirow{2}{*}{$\begin{array}{l}\text { Solubility } \\
\text { in DMF }\end{array}$} & \multicolumn{3}{|c|}{ Elemental analysis } & \multirow{2}{*}{$\begin{array}{l}\%) \\
\mathrm{Cl}\end{array}$} & \multirow{2}{*}{$\begin{array}{l}\mathrm{Cl} / \mathrm{N} \\
(\mathrm{mol} / \mathrm{mol})\end{array}$} & & \\
\hline & & & $\mathrm{C}$ & $\mathrm{H}$ & $\mathrm{N}$ & & & & \\
\hline 0.10 & NP & soluble & 85.8 & 7.4 & 1.4 & 3.1 & 0.87 & 12 & 11 \\
\hline 0.21 & NP & soluble & 82.0 & 7.2 & 2.3 & 5.3 & 0.91 & 21 & 19 \\
\hline 0.31 & NP & soluble & 79.6 & 6.8 & 2.8 & 6.9 & 0.98 & 26 & 25 \\
\hline 0.52 & NP & gel & ND & ND & ND & ND & ND & ND & ND \\
\hline 1.10 & NP & gel & ND & ND & ND & ND & ND & ND & ND \\
\hline 0.10 & NB & soluble & 86.2 & 7.5 & 1.7 & 2.7 & 0.63 & 14 & 12 \\
\hline 0.21 & NB & soluble & 81.8 & 7.2 & 2.4 & 5.4 & 0.89 & 22 & 22 \\
\hline 0.35 & NB & gel & ND & ND & ND & ND & ND & ND & ND \\
\hline 0.71 & NB & gel & ND & ND & ND & ND & ND & ND & ND \\
\hline 0.95 & NB & soluble & ND & ND & ND & ND & ND & ND & ND \\
\hline 1.10 & NB & soluble & 61.9 & 5.6 & 6.6 & 15.5 & 0.93 & 98 & 96 \\
\hline
\end{tabular}

RU: repeating unit of polymer, ND: not determined, NP: 1-nitropropane, NB: nitrobenzene.

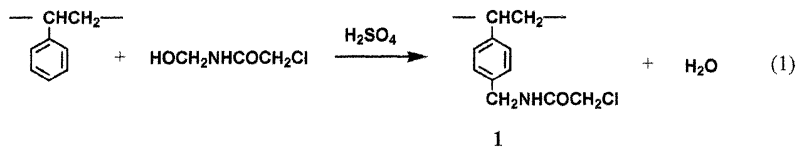

Scheme 1.

\section{RESULTS AND DISCUSSION}

\section{Amidomethylation Reaction of Polystyrene}

We investigated the amidomethylation of polystyrene (polyST)s with NMCA in nitrobenzene or 1nitropropane in the presence of sulfuric acid as catalyst, as shown in Formula 1 in Scheme 1. These results and conditions were summarized in Table I. When 1.1 molar of NMCA to a repeating unit of polySTs was used in the amidomethylation in nitrobenzene, the chloroactamidomethyl group substituted all benzene rings of the resulting polymers. The resulting poly(4chloroacetamidomethyl styrene)s were soluble in only DMF and insoluble in other solvents, such as DMSO and chloroform. However, when the same reaction was carried out in 1-nitropropane, the resulting polymer was insoluble in DMF as well as the results in the previous paper. ${ }^{7}$ Furthermore, when less amount of NMCA than 1 molar ratio was used in the amidomethylation in 1-nitropropane or nitrobenzene, soluble polymers were obtained only in limited range of molar ratios. The soluble polymer was obtained at a molar ratio of 0.10 , 0.21 , or 0.31 in 1-nitropropane, and at a molar ratio of $0.02,0.10,0.21$, or 0.95 in nitrobenzene, whereas the whole reaction mixture gelled at a molar ratio of more than 0.52 in 1-nitropropane and at that of 0.35 or 0.7 in nitrobenzene. Thus whether the obtained polymer was soluble or not depends on the amount of

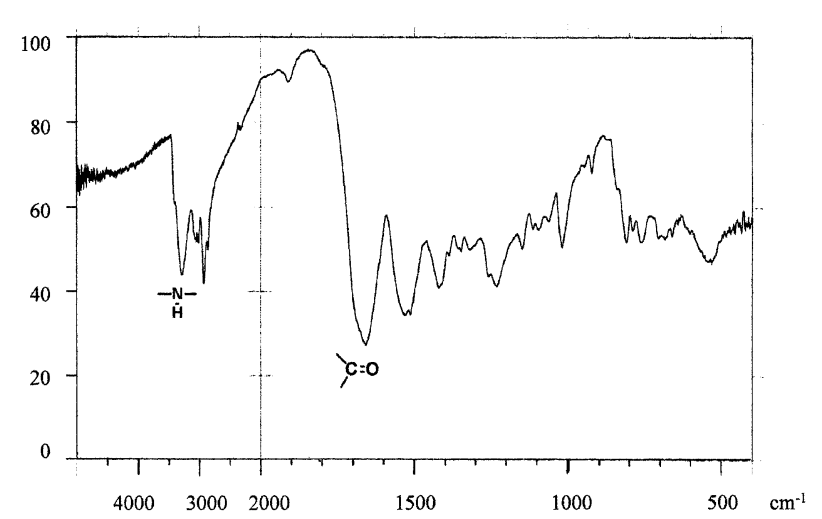

Figure 1. FT-IR spectra of poly(4-chloroacetamidomethylstyrene) in $\mathrm{KBr}$ disk.

added NMCA. Since $\mathrm{Cl} / \mathrm{N}$ ratios in Table I indicate the ratio of chloroacetyl group per amidomethylated benzene ring, they should be 1 theoretically, but they were smaller than 1 practically. It is because a part of the chloroacetyl residue was eliminated by hydrolysis.

The structure of the resulting polymers, poly(4chloroacetamidomethyl styrene)s was confirmed by the ${ }^{1} \mathrm{H}$ NMR and IR spectroscopy, besides elemental analysis. As shown in Figure 1, the IR spectrum of poly(4-chloroacetamidomethyl styrene) that was obtained in amidomethylation of polyST with NMCA $(\mathrm{NMCA} / \mathrm{PST}=1.10)$ in nitrobenzene showed the signals assignable to amide bonds at 3308, 1657, and 1529 $\mathrm{cm}^{-1}$. The elemental analysis date showed that the nitrogen and chlorine were contained in the obtained polymers. These results strongly supported that almost all benzene rings of polyST were substituted with NMCA to produce the chloroacetamidomethyl groups.

Amidomethylation, as well as nitration, sulfonation, halogenation, and Friedel-Crafts acylation, is an electrophilic aromatic substitution reaction, and gives 


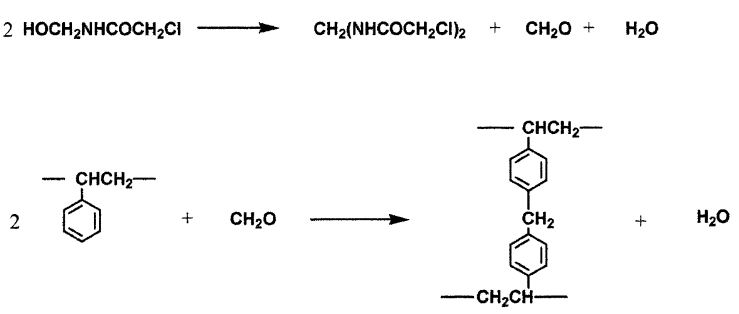

Scheme 2.

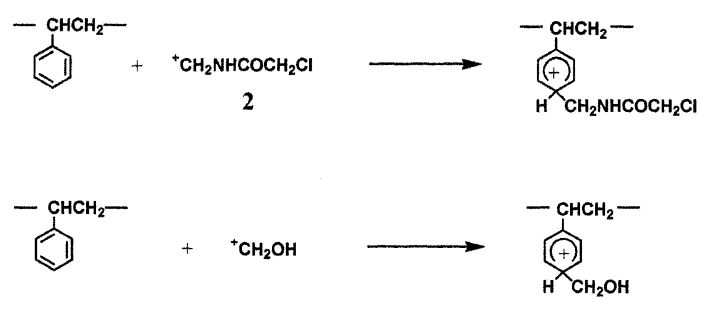

(4)

(2)

Scheme 3.

ortho- and para-isomer in the case of toluene ${ }^{10}$ of which structure is the same as that of polystyrene. In the previous paper NMR analysis of the aminomethyl polystyrene gel that was prepared by hydrolysis of a chloroacetamidomethylated polystyrene gel showed that the substitution position was para-position. ${ }^{7}$ Judging from these results, the structure is considered to be 1 in Scheme 1.

The cause of the gel formation is considered to be due to formaldehyde produced by decomposition ${ }^{10}$ of NMCA (Formulas 2 and 3 in Scheme 2). Formaldehyde causes the crosslinking of the aromatic polymer in analogy with toluene-formaldehyde resin. ${ }^{11}$ However, the question of why soluble polymer was obtained in 1.1 of the molar ratio of NMCA in nitrobenzene, although formaldehyde is probably formed more in 1.1 than in 0.3 of the molar ratio, rises. In addition, there is also the question why the gel polymer was still obtained at 1.1 molar of NMCA in the 1-nitropropane solution ${ }^{7}$ in contrast with in the nitrobenzene. To the former question it is suggested that chloroacetamidomethyl carbonium ion ( 2 in Scheme 3 ) reacts with benzene ring before formaldehyde does, because the amidomethylation reaction proceeds faster than the crosslinking reaction (Formula 5 in Scheme 3). To the latter question we presume the reason is due to difference of their precipitates as given below, since we experienced that gel was always obtained without sufficient stirring at the early stage of the reaction. Namely, the reacted polystyrene that precipitated in 1-nitropropane is partially amidomethylated, and has room to react with formaldehyde to produce crosslinking. On the other hand, the precipitate in nitrobenzene no longer may have room to react with formaldehyde because it is completely amidomethylated, and therefore is soluble.

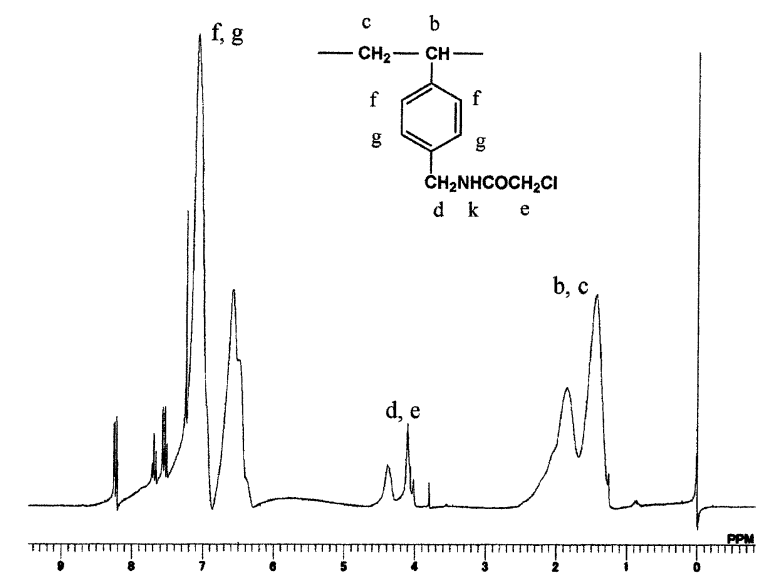

Figure 2. $270 \mathrm{MHz}{ }^{1} \mathrm{H}$ NMR spectrum of partially chloroacetamidomethylated polystyrene ( $\mathrm{N}$ content; $1.4 \%$ ) in $\mathrm{CDCl}_{3}$ at $30^{\circ} \mathrm{C}$.

\section{Estimation of the Degree of Substitution}

One method for determining the degree of substitution (DS) by chloroacetamidomethyl group in amidomethylation is the elemental analysis. Since the number of nitrogen atoms is equal to that of the introduced chloroacetamidomethyl group, DS was calculated, on the assumption that hydrolysis did not occurred, according to the following equation:

$$
D S=n M(1401-105.5 n)^{-1}
$$

where $n$ is $\%$ nitrogen content, and $M$ is the molecular weight of intact polymer. Another is the ${ }^{1} \mathrm{H}$ NMR method. The amount of benzyl and acetyl protons $(d, e)$ per other aliphatic protons $(b, c)$ in the spectrum indicates DS (Figure 2). In the case of polystyrene the doublet peaks at $4.06 \mathrm{ppm}$ and $4.10 \mathrm{ppm}$ are due to benzyl protons and the peak at $4.38 \mathrm{ppm}$ is due to acetyl protons. On the other hand, the peak of benzyl protons overlaps with that of acetyl protons in poly(methylstyrene) (Figure 5). DS from the elemental analysis method was in fair agreement with DS from the ${ }^{1} \mathrm{H}$ NMR method in the case of polystyrene and poly(4-methylstyrene).

\section{Amidomethylation Reaction of Poly(methylstyrene)}

When poly(3(4)-methylstyrene) which comprises of meta $60 \%$ and para $40 \%$ was reacted with 1.1 molar of NMCA in nitrobenzene in the presence of sulfuric acid, it gave soluble and highly amidomethylated polymer. It shows strong peaks of amide bond at 3290, 1659, and $1528 \mathrm{~cm}^{-1}$ in IR spectrum (solid line in Figure 3). Since the peak of $1659 \mathrm{~cm}^{-1}$ disappears after hydrolysis by hydrochloric acid (dotted line in Figure 3 ), the introduction of the amide bond was confirmed.

Similarly when poly(4-methylstyrene) was treated with 1.1 molar of NMCA, it also gave soluble polymer which showed amide bonds at 3300, 1660, and 
Table II. Amidomethylation reaction of poly(4-methylstyrene)

Poly(4-methylstyrene) solution $(6.0 \mathrm{~g}$ in $100 \mathrm{~mL}$ of nitrobenzene) was mixed with amidomethylating solution and stirred for $2 \mathrm{~h}$ at room temperature. Amidomethylating solution; NMCA 5.4\%, sulfuric acid $71.0 \%$, nitrobenzene $23.6 \%$

\begin{tabular}{|c|c|c|c|c|c|c|c|c|}
\hline \multirow{3}{*}{$\begin{array}{l}\text { Reaction conditions } \\
\text { NMCA/RU } \\
(\mathrm{mol} / \mathrm{mol})\end{array}$} & \multicolumn{6}{|c|}{ Reaction products } & \multirow{3}{*}{$\begin{array}{l}\mathrm{DS} \\
\text { from } \mathrm{N} \text { content } \\
(\%)\end{array}$} & \multirow{3}{*}{$\begin{array}{l}\mathrm{DS} \\
\text { from NMR } \\
(\%) \\
\end{array}$} \\
\hline & \multirow{2}{*}{$\begin{array}{l}\text { Solubility } \\
\text { in DMF }\end{array}$} & \multicolumn{3}{|c|}{ Elemental analysis } & \multirow{2}{*}{$\begin{array}{l}\%) \\
\mathrm{Cl} \\
\end{array}$} & \multirow{2}{*}{$\begin{array}{l}\mathrm{Cl} / \mathrm{N} \\
(\mathrm{mol} / \mathrm{mol})\end{array}$} & & \\
\hline & & $\mathrm{C}$ & $\mathrm{H}$ & $\mathrm{N}$ & & & & \\
\hline 0.11 & soluble & 89.3 & 8.4 & 0.5 & 1.7 & 1.35 & 4.4 & ND \\
\hline 0.22 & soluble & 86.6 & 8.1 & 1.1 & 2.8 & 1.01 & 10 & 11 \\
\hline 0.33 & soluble & 84.6 & 7.9 & 1.5 & 4 & 1.06 & 14 & 15 \\
\hline 0.44 & soluble & 82.2 & 7.7 & 2.1 & 5.1 & 0.96 & 21 & 23 \\
\hline 0.55 & soluble & 80.3 & 7.5 & 2.5 & 6.1 & 0.97 & 26 & 25 \\
\hline 0.77 & gel & ND & ND & ND & ND & ND & ND & ND \\
\hline 1.03 & soluble & 63.3 & 6.4 & 6.1 & 14.8 & 0.95 & 96 & 107 \\
\hline
\end{tabular}

RU: repeating unit of polymer, ND: not determined.

Table III. Amidomethylation reaction of poly(4-tert-methylstyrene)

Poly(4-tert-methylstyrene) solution $(2.3 \mathrm{~g}$ in $100 \mathrm{~mL}$ of nitrobenzene) was mixed with amidomethylating solution and stirred for $2 \mathrm{~h}$ at room temperature. Amidomethylating solution; NMCA 5.7\%, sulfuric acid 73.8\%, 1-nitrobenzene 20.5\%

\begin{tabular}{|c|c|c|c|c|c|c|c|}
\hline \multirow{3}{*}{$\begin{array}{l}\text { Reaction conditions } \\
\mathrm{NMCA} / \mathrm{RU} \\
(\mathrm{mol} / \mathrm{mol})\end{array}$} & \multicolumn{6}{|c|}{ Reaction products } & \multirow{3}{*}{$\begin{array}{l}\text { DS } \\
\text { from NMR } \\
(\%)\end{array}$} \\
\hline & \multirow{2}{*}{$\begin{array}{l}\text { Solubility } \\
\text { in DMF }\end{array}$} & \multicolumn{3}{|c|}{ Elemental analysis } & \multirow{2}{*}{$\begin{array}{l}(\%) \\
\mathrm{Cl}\end{array}$} & \multirow{2}{*}{$\begin{array}{l}\mathrm{Cl} / \mathrm{N} \\
(\mathrm{mol} / \mathrm{mol})\end{array}$} & \\
\hline & & $\mathrm{C}$ & $\mathrm{H}$ & $\mathrm{N}$ & & & \\
\hline 0.11 & soluble & 89.1 & 9.6 & 0.17 & 0.6 & 1.41 & ND \\
\hline 0.22 & soluble & 88.0 & 9.7 & 0.42 & 1.3 & 1.23 & 1.2 \\
\hline 0.34 & soluble & 87.2 & 9.8 & 0.67 & 1.6 & 0.94 & 3.4 \\
\hline 0.45 & soluble & 84.4 & 9.3 & 1.3 & 3.2 & 0.98 & 8.0 \\
\hline 0.56 & soluble & 83.3 & 9.3 & 1.5 & 3.7 & 0.99 & 8.4 \\
\hline 0.79 & soluble & 81.1 & 9.0 & 2.0 & 4.9 & 0.97 & 13 \\
\hline 1.14 & soluble & 78.9 & 8.8 & 2.5 & 6.1 & 0.95 & 15 \\
\hline
\end{tabular}

RU: repeating unit of polymer, ND: not determined.

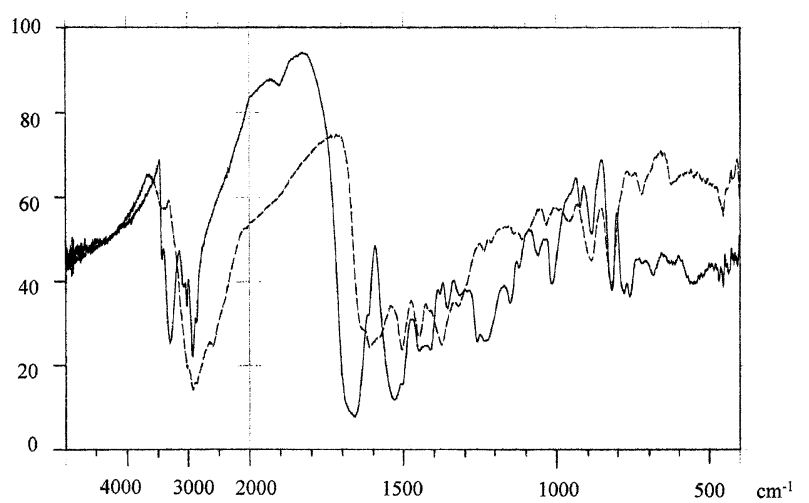

Figure 3. FT-IR spectra of chloroacetamidomethylated poly(3(4)-methyl-styrene) in $\mathrm{KBr}$ disk (solid line- before hydrolysis, dotted line- after hydrolysis).

$1536 \mathrm{~cm}^{-1}$ originated from amide bond and that at $764 \mathrm{~cm}^{-1}$ from $\mathrm{C}-\mathrm{Cl}$ bond in the IR spectrum. After hydrolysis of the polymer by hydrochloric acid, peaks of primary amino group appeared at 3361 and 3283 $\mathrm{cm}^{-1}$ in the IR spectrum instead of those of the amide bonds at 1660 and $1536 \mathrm{~cm}^{-1}$. Elemental analysis of the amidomethylated polymer shows that one hydrogen atom in the benzene ring was substituted with chloroacetamidomethyl group. Table II shows the results of amidomethylation of poly(4-methylstyrene) in various molar ratio of NMCA. When the molar ratio of NMCA
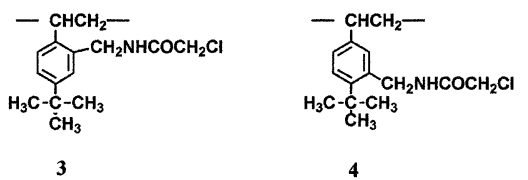

Scheme 4.

to benzene ring was not more than 0.55 , soluble polymers were obtained. However, gel was formed at a ratio of 0.77 . Judging from ${ }^{1} \mathrm{H}$ NMR and elemental analysis, the substitution ratio by chloroacetamidomethyl group in these soluble polymers was 0.05 to 0.26 .

\section{Amidomethylation Reaction of Poly(4-tert-butylsty- rene)}

Poly(4-tert-butylstyrene) was amidomethylated in 1-nitropropane at room temperature, because it was hardly soluble in nitrobenzene. During the reaction, some black precipitate was produced temporarily, but it gradually dissolved in the solution with the elapse of time under stirring. The reaction product contained nitrogen and chlorine by the elemental analysis, and showed two peaks of amide at 1688 and $1682 \mathrm{~cm}^{-1}$ in the IR spectrum. These results suggest that the structure is $\mathbf{3}$ and $\mathbf{4}$ in Scheme 4. Table III shows the relation of the molar ratio of NMCA and DS in this reaction. No gel was obtained in all molar ratios of NMCA, 


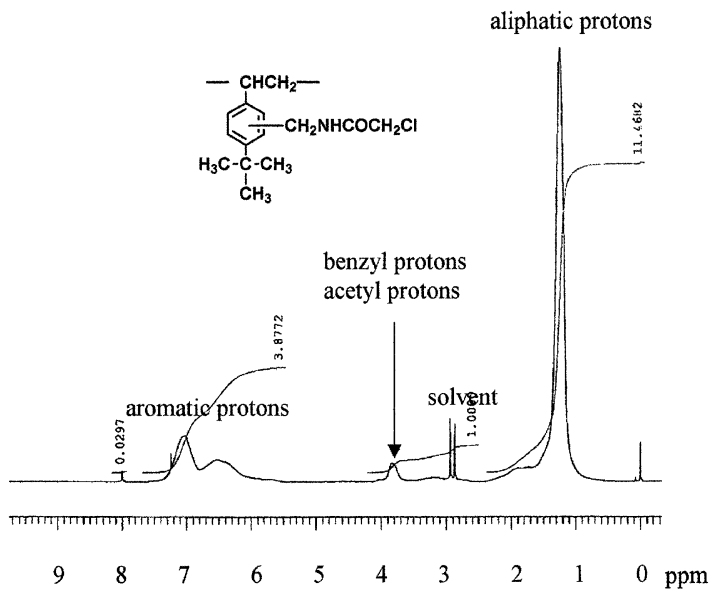

Figure 4. $270 \quad \mathrm{MHz} \quad{ }^{1} \mathrm{H} \quad \mathrm{NMR}$ spectra of chloroacetamidomethylated poly(4-t-butyl-styrene) ( $\mathrm{N}$ content; 2.2\%) in $\mathrm{CDCl}_{3}$ at $30^{\circ} \mathrm{C}$.

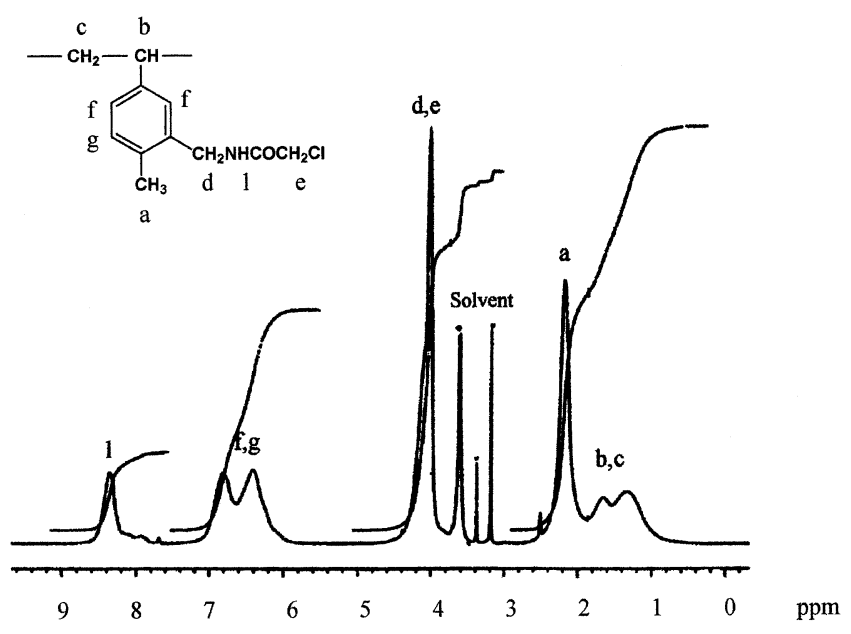

Figure 5. $400 \mathrm{MHz} \quad{ }^{1} \mathrm{H} \quad \mathrm{NMR}$ spectrum of chloroacetamidomethylated poly(4-methyl-styrene) ( $\mathrm{N}$ content; 6.1\%) in DMSO- $d_{6}$ at $30^{\circ} \mathrm{C}$.

but DS of the resultant polymers were low. Even when $2.4 \mathrm{~mol}$ of NMCA were used, the substitution rate did not exceed $15 \%$ (from ${ }^{1} \mathrm{H}$ NMR). It is considered to be due to steric hindrance by 4-tert-butyl group, which prevents access of two benzene rings for crosslinking formation. The ${ }^{1} \mathrm{H}$ NMR spectrum was shown in Figure 4 , where the peak at $3.83 \mathrm{ppm}$ was due to chloroacetamidomethyl group. The peak of benzyl protons can overlap with that of acetyl protons.

\section{Substitution Position}

Amidomethylation is ortho-para directing reaction. In the case of poly(4-methylstyrene), 1,4-disubstitution compound, it can be substituted at the 2- and the 3-position by chloroacetamidomethyl group. The ${ }^{1} \mathrm{H}$ NMR spectrum and the ${ }^{13} \mathrm{C}$ NMR spectrum of chloroacetamidomethylated poly(4-methylstyrene) are shown in Figures 5 and 6, respectively. The peak at $4.03 \mathrm{ppm}$ in the ${ }^{1} \mathrm{H}$ NMR spectrum is assigned to hy-

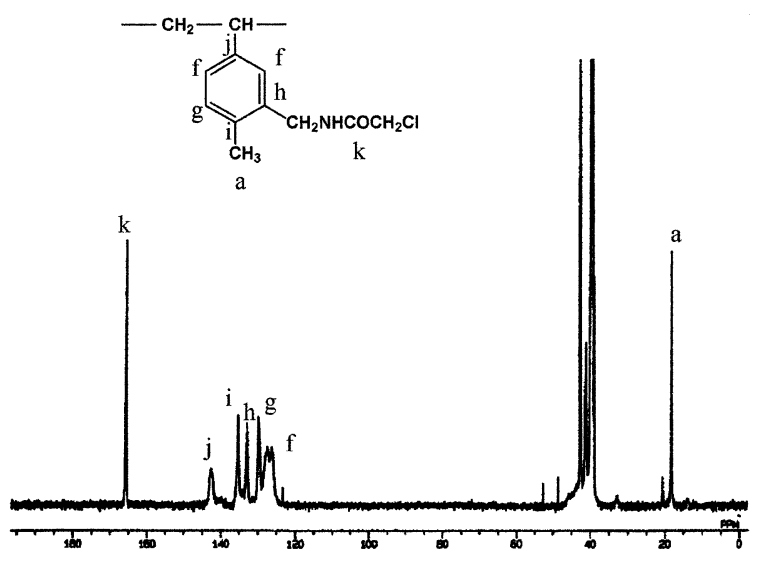

Figure 6. $100 \mathrm{MHz}{ }^{13} \mathrm{C} \quad \mathrm{NMR}$ spectrum of chloroacetamidomethylated poly(4-methyl-styrene) (N content; 6.1\%) in $\mathrm{DMSO}-d_{6}$ at $30^{\circ} \mathrm{C}$.

Table IV. Chemical shift of chloroacetamidomethylated poly(4-methylstyrene)

\begin{tabular}{cccc}
\hline Position at chemical structure & ${ }^{1} \mathrm{H} \mathrm{NMR}$ & & ${ }^{13} \mathrm{C} \mathrm{NMR}$ \\
5 in Scheme 5 & $\mathrm{ppm}$ & & $\mathrm{ppm}$ \\
\hline a & 2.18 & & 18.22 \\
b, c & $0.6-2.8$ & $37-46$ \\
d & 4.03 & 41.06 \\
e & 4.03 & 42.50 \\
f, g & $5.8-7.4$ & $125-133$ \\
h & - & 132.82 \\
i & - & 135.22 \\
j & - & 142.57 \\
k & - & 165.65 \\
1 & $7.6-8.8$ & - \\
\hline
\end{tabular}

drogen $(4 \mathrm{H})$ of $\mathrm{d}$ and e in the chloroacetamidomethyl group. The ${ }^{13} \mathrm{C}$ NMR spectrum assigned peaks of $d$ and e to the chloroacetamidomethyl group by comparing with the spectrum of poly(4-methylstyrene). The small peak at $20.65 \mathrm{ppm}$ in the neighborhood of the large peak at $18.22 \mathrm{ppm}$ is assigned to the methyl carbon of the intact polymer. Other assignments were summarized in Table IV. The substituted density is calculated to be 1.07 from the ratio of the peak area of $d$ and e to that of a in the ${ }^{1} \mathrm{H}$ NMR spectrum. The HMBC spectrum is shown in Figure 7. It shows that the methyl protons $(3 \mathrm{H}$; a) strongly correlate with the aromatic carbon (i) bonded to methyl group, an aromatic carbon (g) binding hydrogen, and an aromatic carbon (h) bonded with chloroacetamidomethyl group. Furthermore, the interaction of the methyl protons $(3 \mathrm{H}$; a) and two aromatic carbons (f) binding hydrogen or benzyl carbon (d) of amidomethyl group was slightly observed. These results support the structure 5 (meta substitution: Scheme $5)$.

In the case of poly(4-tert-butylstyrene), it is considered that structures $\mathbf{3}$ and $\mathbf{4}$ were produced, because two peaks of amide 1 were observed in IR spectrum. The 


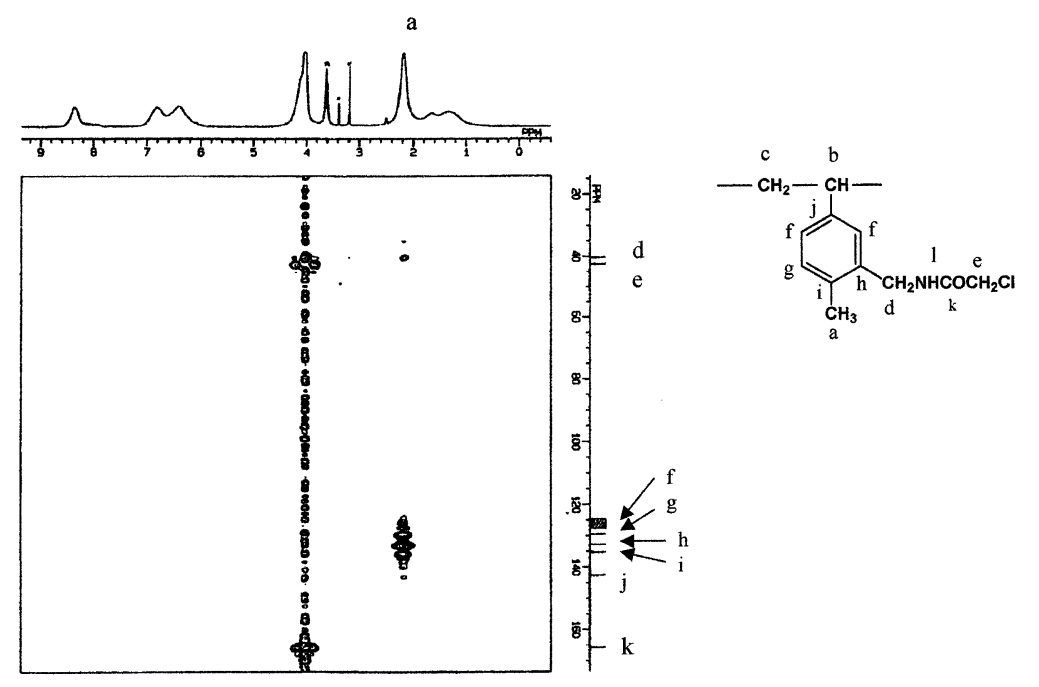

Figure 7. $400 \mathrm{MHz} \mathrm{HMBC}$ spectra of chloroacetamidomethylated poly(4-methyl-styrene) (N content; $6.1 \%$ ) in DMSO- $d_{6}$ at $30^{\circ} \mathrm{C}$.

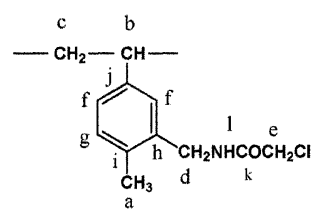

5

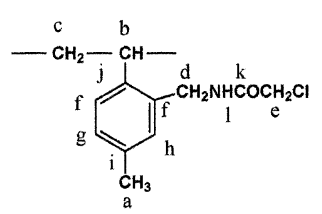

6
Scheme 5.

difference in the substitution position between poly(4methylstyrene) and poly(4-tert-butylstyrene) is due to the difference in their steric hindrance.

\section{Characteristic of Amidomethylated Polymer}

The polymers, of which benzene rings were fully substituted by chloroacetamidomethyl group, were soluble in DMF but not in chloroform. These polymers lose their film-forming property. The partially substituted ones were soluble in DMF and in chloroform, and give a tough film from DMF solution.

\section{CONCLUSION}

New soluble vinyl aromatic compound polymers containing 2-chloro-acetamidomethyl group were prepared from the corresponding polymers by amidomethylation with $N$-methylol-2-chloroacetamide (NMCA). The reaction proceeded in nitrobenzene or nitropropane in the presence of sulfuric acid as catalyst at a temperature of 10 to $25^{\circ} \mathrm{C}$.

\section{REFERENCES}

1. H. H. Roth, Ind. Eng. Chem., 46, 2435 (1954). H. H. Roth, Ind. Eng. Chem., 59, 1820 (1957).

2. J. A. Blanchette and J. D. Cotman, J. Org. Chem., 23, 1117 (1958).

3. G. B. Bachman, H. Hellman, K. R. Robinson, R. W. Finholt, E. J. Kahler, L. J. Filar, L. V. Heisey, L. L. Lewis, and D. D. Micucci, J. Org. Chem., 12, 108 (1947).

4. K. W. Pepper, H. M. Paisley, and M. A. Young, J. Chem. Soc., 4097 (1953).

5. A. R. Mitchell, S. B. H. Kent, B. W. Erickson, and R. B. Merrifield, Tetrahedron Lett., 42, 3795 (1976).

6. M. Shimamura, K. Teramoto, T. Yoshioka, and M. Tanaka, 'Polystyrene-based functional fibers' in "Handbook of Fiber Science and Technology, vol. 3, High Technology Fibers, Part B”, M. Lewin and J. Preston Ed., Mercel Dekker, New York and Basel, 1989, chapt. 7.

7. K. Teramoto, Reactive Polymers, 15, 89 (1991).

8. K. Teramoto, Y. Ogawa, T. Sudo, N. Nakamura, and S. Kobayashi, Tiss. Cul. Res. Commun., 11, 329 (1992).

9. M. Kodama, T. Tani, K. Hanazawa, K. Teramoto, and S. Nishiumi, Therap. Apher., 4, 142 (2000).

U. S. Patent 04661260 (April 28, 1987).

10. H. E. Zaugg and W. B. Martin, "Organic Reactions", John Wiley \& Sons. Inc., New York, N.Y., 1965, vol. 14, p 52.

11. M. Imoto, C. Y. Huang, T. Iguchi, F. Sakurai, T. Kuraya, S. Yoshida, T. Uehara, and J. Itakura, Makromol. Chem. 43, 189 (1961). 